\title{
FOREIGN DIRECT INVESTMENT (FDI), KEBIJAKAN INDUSTRI, DAN MASALAH PENGANGGURAN: STUDI EMPIRIK DI INDONESIA
}

\author{
Syamsudin ${ }^{1}$ \\ Anton A Setyawan ${ }^{1}$ \\ ${ }^{1}$ Fakultas Ekonomi Universitas Muhammadiyah Surakarta, Jawa Tengah \\ E-mail: syamsudin@ums.ac.id; rmb_anton@yahoo.com
}

\begin{abstract}
Unemployment has become one of the major problems in Indonesia in the last eight years. SBY administration decides many economic policies in order to overcome the problem, but it seems not enough. However, the rate of foreign direct investment in Indonesia is increasing in the last three years. Macroeconomic indicators show that everything in its right track. This research analyzes the effects of FDI rate to employment rate in Indonesia. This research uses empirical data from ADB from 1983-2004. This research uses error correction model as a tool of analyses. The result shows that FDI rate does not have effect to employment rate. It means that FDI does not open job opportunity for many unemployer in Indonesia. In the end, this paper discusses the possibility of industrial policy in order to provide direction for government to develop Indonesia's industry.
\end{abstract}

Keywords: unemployment, foreign direct investment, industrial policy, ECM

\section{PENDAHULUAN}

Berdasarkan data dari Biro Pusat Statistik (BPS) jumlah pengangguran terbuka di Indonesia sampai dengan bulan Februari tahun 2008 ini mencapai 9,43 juta orang atau 10 persen dari total angkatan kerja. Angka ini mengalami penurunan dari bulan Februari tahun 2007 yang mencapai angka 10,2 juta orang. Meskipun ada sedikit penurunan, namun jumlah penganggur terbuka tetap besar. Besarnya jumlah pengangguran ini kontradiktif dengan kecenderungan perbaikan indikator ekonomi makro, seperti angka inflasi di bawah dua digit, penguatan kurs Rupiah yang mencapai Rp 9.000 per Dollar AS dan terutama indeks harga saham BEJ yang mencapai angka di atas 2000 poin selama tahun 2007 ini. Data investasi langsung juga mengalami perbaikan, yang ditandai dengan peningkatan investasi dalam negeri (PMDN) sebesar 43 persen, sedangkan investasi asing (PMA) mengalami peningkatan sebesar 23 persen pada tahun 2004 lalu. Perbaikan indikator makro ekonomi ini tidak diikuti dengan perbaikan sektor riil. Data ekspor menunjukkan adanya penurunan sebesar 3,9 persen pada tahun 2005. Pengangguran dan kemiskinan selalu berkorelasi karena masyarakat yang menganggur tidak produktif dan pasti menambah jumlah masyarakat miskin. Maka mengatasi pengangguran akan berdampak 
pada pengurangan jumlah orang miskin. Namun demikian, mengatasi masalah pengangguran dan kemiskinan tidak semudah membalik telapak tangan. Banyak kasus perencanaan pembangunan di negara berkembang yang mengalami kegagalan dalam mengatasi masalah kemiskinan dan pengangguran. Indonesia pada masa Orba adalah contoh yang baik dalam menggambarkan sulitnya mengatasi masalah pengangguran. Pada masa Orba dari dekade awal 80-an sampai dengan pertengahan 90-an Indonesia dikenal sebagai salah satu calon Macan Industri Asia karena pertumbuhan ekonomi yang tinggi (di atas 7 persen). Pada masa deKade 80-an, angka pengangguran di Indonesia hanya sekitar 2 persen, akan tetapi pada saat awal 90-an, angka pengangguran terbuka melonjak menjadi 6 persen. Padahal pada masa itu, ekonomi Indonesia masih mengalami booming.

Para pengamat memperkirakan besarnya jumlah penganggur pada saat terjadi peningkatan angka investasi langsung maupun portofolio dikarenakan peningkatan investasi langsung bukan pada sektor-sektor padat karya melainkan padat modal. Untuk memperkuat perkiraan para pengamat ini, penulis melakukan simulasi dengan model ekonometrik yang menganalisis hubungan antara jumlah orang yang bekerja (employed) dengan angka investasi langsung.

Masalah pengangguran merupakan hal yang krusial dalam perekonomian negeri ini. Salah satu indicator keberhasilan program ekonomi pemerintah SBY adalah mengurangi jumlah penganggur di Indonesia. Pemerintah SBY mempunyai target ambisius terkait dengan pengurangan jumlah pengangguran ini. Target pemerintah pada tahun 2009, angka pengangguran terbuka bisa dikurangi hingga mencapai 5 persen dari total angkatan kerja. Berdasarkan data yang ada maka sulit mencapai target ini dalam sisa waktu pemerintahan SBY.

Pada bulan Maret 2006 lalu, pemerintah mengeluarkan Inpres No 3 tahun 2006 yang isinya tentang kebijakan umum yang akan dilakukan pemerintah dalam memperbaiki iklim investasi. Perbaikan iklim investasi dimaksudkan untuk mengundang investor asing agar bersedia menanamkan modalnya di Indonesia dalam bentuk FDI (Foreign Direct Investment). Selain itu, inpres ini juga ditunjukkan untuk mencegah pengusaha Indonesia agar tidak melarikan modalnya ke luar negeri. Pemerintah Indonesia percaya bahwa investasi langsung dalam wujud pembangunan pabrik-pabrik baru akan membuka tambahan lapangan pekerjaan baru yang cukup menyerap pertumbuhan tenaga kerja baru di Indonesia. Lipsey dan Sjoholm (2004) dalam penelitiannya yang menganalisis peran investasi asing langsung (FDI) di Indonesia berperan dalam membuka lapangan pekerjaan bagi tenaga kerja terdidik. Selain itu, FDI juga memberikan sumbangan bagi industri manufaktur Indonesia terutama dari sisi teknologi.

Artikel ini menganalisis keterkaitan antara angka investasi asing langsung (FDI) dengan jumlah orang yang bekerja di Indonesia dengan data dari Asian Development Bank dari tahun 1983-2003. Artikel ini menganalisis benarkah tambahan investasi langsung akan serta merta mengurangi pengangguran terbuka. Alat analisis yang digunakan adalah regresi dengan model Error Correction Model (ECM) dengan pendekatan First Order ECM. Penggunaan alat analisis ini dimaksudkan untuk menghindari terjadinya regresi lancung (Insukindro, 1991). 
Tinjauan pustaka dalam penelitian ini sebagai berikut:

\section{Masalah Pengangguran di Indonesia}

Teori pembangunan mainstream ala negara maju selalu mengemukakan bahwa pembangunan adalah transfer manusia dan aktivitas ekonomi secara terus menerus dari pedesaan ke perkotaan. Kondisi ini terjadi karena dua hal, pertama, ekspansi industri perkotaan menimbulkan penciptaan lapangan pekerjaan baru. Kedua, kemajuan teknologi mengakibatkan industri lebih bersifat padat modal sehingga mengurangi permintaan terhadap tenaga kerja, terutama di sektor pertanian. Saran yang selalu disampaikan oleh ekonom negara maju kepada pemerintahan negaranegara berkembang adalah agar mereka berupaya untuk melakukan percepatan ekspansi industri terutama di perkotaan sehingga daerah perkotaan menjadi sentra pertumbuhan ekonomi. Tetapi beberapa negara berkembang di kawasan Pasifik Selatan mengalami kegagalan dalam melaksanakan kebijakan tersebut karena kemampuan adaptasi teknologi yang rendah (Zulkieflimansyah, 2000). Kondisi di Indonesia, rupanya tidak jauh berbeda, orientasi industri substitusi impor tanpa kemampuan teknologi yang mencukupi ternyata berimplikasi pada tingginya angka pengangguran.

Menurut definisi dari Badan Pusat Statistik (BPS), pengangguran di Indonesia diklasifikasikan menjadi dua kelompok besar, pertama, pengangguran terbuka, yaitu seluruh angkatan kerja yang mencari kerja, baik para pencari kerja baru (first time job), maupun mereka yang sebelumnya pernah bekerja. Kedua, setengah pengangguran, yaitu mereka yang bekerja kurang dari 35 jam dalam seminggu. Ironisnya, kontradiktif dengan teori pembangunan mainstream di atas, angka pengangguran di Indonesia justru lebih banyak di perkotaan, karena industri yang rata-rata padat modal (teknologi) membutuhkan kualifikasi SDM yang mampu beradaptasi dengan teknologi, namun kebanyakan angkatan kerja di Indonesia tidak mempunyai kemampuan tersebut.

Menurut Kuncoro (2000) dengan menggunakan pendekatan angkatan kerja, pengangguran terbagi menjadi tiga jenis, yaitu, pertama, pengangguran friksional. Pengangguran jenis ini adalah pengangguran yang muncul karena pencari kerja masih mencari pekerjaan yang sesuai jadi ia menganggur bukan karena tidak ada pekerjaan. Pengangguran ini tidak menimbulkan masalah, dan bisa diselesaikan dengan pertumbuhan ekonomi. Kedua, pengangguran struktural. Pengangguran struktural adalah pengangguran yang muncul karena perubahan struktur dan komposisi perekonomian. Pengangguran ini sulit diatasi karena terkait dengan strategi pembangunan sebuah negara. Meskipun demikian, pengangguran jenis ini bisa diatasi dengan melakukan pelatihan agar tercipta tenaga kerja terampil. Ketiga, pengangguran musiman. Pengangguran yang terjadi karena factor musim, misalnya para pekerja di industri yang mengandalkan hidupnya dari pesanan. Pengangguran jenis ini juga tidak menimbulkan banyak masalah. Meskipun belum ada bukti empirik yang mendukung, pengangguran yang muncul karena keterpurukan industri sebagian besar adalah pengangguran friksional dan struktural. Pengangguran friksional yang muncul di Indonesia tidak karena menganggur secara "sukarela" melainkan karena kondisi krisis ekonomi. 
Tabel 1. Tabel Angkatan Kerja Indonesia Tahun 2004-2006

\begin{tabular}{lcccc}
\hline Keterangan & Agustus & Februari & November & Februari \\
& $\mathbf{2 0 0 4}$ & $\mathbf{2 0 0 5}$ & $\mathbf{2 0 0 5}$ & $\mathbf{2 0 0 5}$ \\
\hline Angkatan Kerja (juta) & 104 & 105,8 & 105,9 & 106,3 \\
a. Bekerja (juta) & 93,7 & 94,9 & 94 & 95,2 \\
b. Tidak bekerja (penganggur terbuka) & 10,3 & 10,9 & 11,9 & 11,1 \\
Bekerja tidak penuh (juta) & 27,9 & 29,6 & 28,9 & 29,9 \\
a. Sukarela & 14,5 & 15,3 & 15 & 15,7 \\
b. Terpaksa & 13,4 & 14,3 & 13,9 & 14,2 \\
Bukan Angkatan Kerja & 50 & 49,7 & 52,6 & 53 \\
Tingkat Partisipasi Angkatan Kerja/TPAK (\%) & 67,5 & 68 & 66,8 & 66,7 \\
Tingkat Pengangguran Terbuka/TPT(\%) & 9,9 & 10,3 & 11,2 & 10,4 \\
\hline
\end{tabular}

Sumber: Badan Pusat Statistik, www.bps.go.id

Tabel 1 menggambarkan kondisi angkatan kerja dan pengangguran di Indonesia dalam tiga tahun terakhir.

Menurut Dhanani (2004) ada 8 paradoks dalam fenomena pengangguran di Indonesia. Delapan paradoks ini menunjukkan karakteristik pengangguran di Indonesia:

- Pengangguran di perkotaan tiga kali lebih besar daripada pengangguran di pedesaan. Angka pengangguran terbuka di Jakarta adalah yang terbesar di seluruh Indonesia. Lalu mengapa orang-orang terus bermigrasi ke Jakarta? Logika yang dipakai para pencari kerja seharusnya adalah karena lebih banyak orang menganggur di perkotaan, maka lapangan pekerjaan di kota lebih sedikit daripada di desa. Poin ini diperkuat oleh riset dari Byrne dan Strobl (2004) yang mengemukakan di perkotaan pekerjaan lebih dianggap mempunyai arti daripada di wilayah pedesaan.

- Pengangguran terbuka di kalangan kaum muda lebih besar daripada di kalangan dewasa, padahal perusahaan maupun organisasi pemerintah selalu merekrut lulusan baru daripada mereka yang berusia di atas 30 tahun.
- Pengangguran terbuka di kalangan wanita lebih besar daripada pria, padahal perusahaan dan semua sektor modern termasuk industri padat karya manufaktur, supermarket, department store, restoran, bank dan hotel lebih banyak merekrut pekerja wanita.

- Pengangguran terbuka di kalangan pekerja terdidik lebih besar daripada pekerja tidak terdidik. Data tahun 1997 menunjukkan pengangguran terbuka lulusan SMU dan perguruan tinggi mendominasi angka pengangguran terbuka yaitu 60 persen. Namun demikian, permintaan terhadap pendidikan masih tetap tinggi dengan dibukanya perguruan tinggi maupun SMU swasta. Sektor industri merekrut tenaga kerja dengan pendidikan menengah bahkan untuk pekerjaan yang seharusnya membutuhkan skill yang lebih baik, seperti pekerjaan sekretaris dan teknisi.

- $\quad$ Pada level lulusan SMU angka pengangguran terbuka lebih tinggi daripada SMP. Namun demikian, di lapangan kerja tidak ada perbedaan upah yang signifikan antara pekerja lulusan SMU dan SMP.

- Pertumbuhan ekonomi Indonesia sejak pertengahan 1970-an mencapai 7-8 
persen per tahun, namun demikian angka pengangguran terbuka selalu mencapai 2-6 persen per tahun. Apakah ini berarti pertumbuhan ekonomi tidak mampu mengatasi masalah pengangguran?

- Tingkat pengangguran terbuka hampir sama di semua tingkat pendapatan, para pencari kerja dari keluarga miskin tidak mampu menjadi penganggur terbuka, artinya dia harus bekerja dengan tingkat upah berapa pun.

- Tingkat pengangguran terbuka di beberapa propinsi seperti Sumatera Selatan, Aceh, Kalimantan Timur, NTT, Maluku dan Papua lebih besar tiga kali lipat dibandingkan propinsi tetangganya seperti Lampung, NTB dan Kalimantan tengah tanpa ada penjelasan yang pasti.

\section{Investasi dan Iklim Investasi}

Investasi adalah salah satu pembentuk pendapatan nasional (GDP). Dalam teori ekonomi makro, investasi diperoleh dari tabungan domestik, yang terdiri dari tabungan pemerintah, swasta dan individu. Indonesia pada masa Orba mempunyai angka tabungan domestik paling tinggi hanya 30 persen dari
PDB. Suatu negara yang memiliki nilai tabungan domestik rendah harus berpikir lebih keras untuk meningkatkan investasi. Ada dua pilihan yang bisa dilakukan, yaitu hutang luar negeri dan mengundang investor asing. Pilihan pertama adalah hutang luar negeri, namun pilihan ini mengandung resiko membebani APBN. Maka, pilihan yang paling minimal resikonya adalah mengundang investor asing. Sebelum krisis ekonomi tahun 1998, angka investasi asing di Indonesia mencapai 30 persen dari PDB, sementara saat ini tidak pernah mampu melebihi angka 22 persen dari PDB.

Dalam kurun waktu 40 tahun, iklim investasi baik PMDN maupun PMA mengalami perubahan sesuai dengan kondisi sosial politik di Indonesia. Sebagai contoh pada awal Orde Baru dengan Paket UU Penanaman Modal, yaitu UU No. 6 tahun 1968, yang kemudian disempurnakan dengan UU No. 12 tahun 1970 tentang PMDN dan UU No. 1 Tahun 1967 yang disempurnakan dengan UU No. 11 Tahun 1970 tentang PMA, Indonesia membuka peluang seluasluasnya bagi investor untuk menanamkan modalnya di Indonesia.

Tabel 2. Rasio Penanaman Modal Asing di Wilayah Timur dan Barat Indonesia Tahun 1967 sampai dengan 31 Juli 2000

\begin{tabular}{lcccc}
\hline \multirow{2}{*}{ Wilayah } & \multicolumn{2}{c}{ Proyek } & \multicolumn{2}{c}{ Nilai } \\
\cline { 2 - 5 } & Jumlah & $\%$ & US\$ Milliar & $\%$ \\
\hline Bagian Barat & 7406 & 87.72 & 194.289 & 85.03 \\
Bagian Timur & 1037 & 12.28 & 34.189 & 14.96 \\
Total & 8443 & 100.00 & 228.478 & 100.00 \\
\hline
\end{tabular}

Sumber: Dihitung dari "Laporan Investasi Bulanan” terbitan BKPM Juli 2001. 
Tabel 3. Rasio Penanaman Modal Dalam Negeri di Wilayah Timur dan Barat Indonesia Tahun 1967 sampai dengan 31 Juli 2000

\begin{tabular}{lcccc}
\hline \multirow{2}{*}{ Wilayah } & \multicolumn{2}{c}{ Proyek } & \multicolumn{2}{c}{ Nilai } \\
\cline { 2 - 5 } & Jumlah & $\%$ & Miliar Rupiah & $\%$ \\
\hline Bagian Barat & 9096 & 82.01 & 640.752 & 79.15 \\
Bagian Timur & 1995 & 17.99 & 168.823 & 20.85 \\
Total & 11091 & 100.00 & 809.575 & 100.00 \\
\hline
\end{tabular}

Sumber: Dihitung dari “Laporan Investasi Bulanan” terbitan BKPM Juli 2001

Tabel 2 dan Tabel 3 menjadi gambaran bahwa Indonesia dalam masa Orba sampai sekarang begitu "bersahabat" dengan investor. Hal tersebut dikarenakan investor adalah "pintu" yang paling dekat dalam mengatasi masalah-masalah pengangguran, rendahnya akumulasi kapital dan terutama mengejar tingginya tingkat pertumbuhan. Tabel di atas juga menunjukkan bahwa secara akumulatif nilai penanaman modal langsung di Bagian Barat Indonesia jauh lebih besar daripada wilayah Timur Indonesia.

Ada dua jenis investasi yang mempengaruhi pendapatan nasional suatu negara. Pertama, investasi portfolio yaitu investasi yang dilakukan dengan pembelian surat berharga (saham) di pasar bursa. Investasi jenis ini tidak bisa diharapkan stabilitasnya karena investor mempunyai mobilitas modal yang tinggi, tergantung kondisi pasar modal negara bersangkutan. Kedua, investasi langsung. Investasi ini dilakukan investor dengan membangun pabrik baru atau menambah barang modal. Investasi ini mempunyai efek pengganda tinggi karena bisa membuka lapangan pekerjaan baru. Investasi jenis kedua inilah yang diharapkan oleh pemerintah terus masuk ke Indonesia. Dalam publikasi UNCTAD (2004) disebutkan syarat utama sebuah negara menjadi tujuan investasi adalah negara bersangkutan harus mempunyai iklim investasi yang baik. Kishi (2003) mengemukakan negara-negara yang ingin menjadi tujuan investasi harus melakukan konsolidasi pasar uang dan pasar saham dalam negeri mereka. Adapun untuk investasi langsung, selain dua hal itu, perlu juga penerapan corporate governance dalam praktek bisnis maupun sector publik.

Penelitian yang dilakukan Sanyal dan Guvenli (2000) mengemukakan bahwa negara harus meminimalisir campur tangannya terhadap perusahaan asing yang menanamkan modal di negaranya, sehingga mereka bisa beroperasi lebih efisien, karena campur tangan pemerintah biasanya menyebabkan kegagalan pasar. Demirbag dan Mirza (2000) mengemukakan adanya dampak positif perusahaan dalam negeri yang bekerja sama (joint venture) dengan perusahaan asing yaitu transfer teknologi dan budaya profesional.

\section{Riset Empirik FDI dan Pengangguran}

Perkembangan liberalisasi perdagangan mempengaruhi kecepatan ekspansi perusahaan multinasional ke berbagai negara di belahan dunia. Sebagian besar perusahaan multinasional itu mengarahkan ekspansinya ke negara berkembang di Asia. Berdasarkan 
data dari UNCTAD (2004) tiga besar daerah tujuan investasi dunia adalah negara Asia yaitu RRC, Thailand dan India. Hal ini dikarenakan negara-negara Asia (Tenggara) merupakan potensi pasar yang besar bagi produk-produk mereka. Greenaway, Morgan dan Wright (2002) menemukan adanya dampak positif investasi asing di negara berkembang, yaitu pertumbuhan ekonomi negara-negara tujuan investasi menjadi lebih tinggi dibandingkan sebelumnya. Selain itu, investasi asing (langsung) juga membuka lapangan kerja baru bagi para penganggur di negara-negara berkembang. Penelitian lain dari Baier dan Bergstrand (2001) memperkuat argumen ini dengan temuannya bahwa liberalisasi perdagangan memberikan sumbangan besar terhadap peningkatan pertumbuhan ekonomi dunia.

Roy (2004) meneliti pola pengangguran dan industri di India menemukan adanya lag atau jarak waktu antara pembukaan pabrik baru dan tambahan jumlah orang yang bekerja. Hal ini berarti penggunaan angka realisasi investasi langsung lebih bisa memprediksi pembukaan lapangan pekerjaan baru. Penelitian yang dilakukan oleh Ramstetter (2004) dengan data FDI dan angka pengangguran di Thailand tahun 1996-2000 menunjukkan adanya pola ketertarikan para pencari kerja dengan pendidikan tinggi untuk bekerja di perusahaan asing karena standar upah yang lebih tinggi. Maka, pengangguran struktural dan penganggur yang tidak terdidik tidak akan terserap oleh lapangan pekerjaan yang dibuka investor asing.

Perusahaan asing yang masuk sebagai investor di negara berkembang seperti Indonesia tidak bisa dibedakan antara perusahaan yang padat modal atau padat karya. Hal ini dikarenakan pemerintah
Indonesia tidak mempunyai kebijakan industri yang mengarahkan investasi asing untuk menanamkan modalnya pada industriindustri padat karya. Penelitian dari Falk dan Koebel (2004) memberikan kesimpulan yang menarik terkait dengan hal ini. Dalam industri manufaktur, penggunaan teknologi canggih atau komputerisasi ternyata tidak mempunyai efek substitusi yang kuat terhadap penggunaan pekerja tidak terdidik. Namun demikian, industri jasa efek substitusi dari komputerisasi terhadap penggunaan tenaga kerja tidak terdidik sangat besar.

H1 investasi asing langsung berpengaruh positif terhadap peningkatan jumlah orang yang bekerja.

\section{METODE PENELITIAN}

Riset ini menggunakan data set dari Asian Development Bank dengan data time series angka investasi langsung (FDI) dan jumlah orang yang bekerja (employment) dari tahun 1983-2004. Alat analisis yang digunakan adalah regresi dengan model dinamis yaitu ECM (Error Correction Model). Hal ini dilakukan karena data time series cenderung tidak stasioner sehingga mengakibatkan adanya regresi lancung (Gujarati, 2003).

Model ECM yang digunakan dalam penelitian ini adalah First Order ECM mengacu pada Insukindro (1991). Pembentukan model dinamik ECM dalam penelitian ini mengacu pada Insukindro (1999) dengan langkah-langkah berikut ini. Model utama menggambarkan hubungan bahwa jumlah orang yang bekerja (employed) dijelaskan oleh angka investasi langsung (FDI) atau dalam persamaan ini dinamakan dirinvt (direct investment). Maka model ini dapat ditulis sebagai: 
$\mathrm{g}_{3}$ Employed $_{\mathrm{t}-1}$

Employed ${ }_{t}=a_{0}+a_{1}$ Dirivt

Pada saat Employed berada pada titik keseimbangan terhadap Dirvt maka persamaan (1) terpenuhi. Masalahnya dalam kondisi nyata yang terjadi adalah ketidakseimbangan sehingga Employed Emempunyai nilai yang berbeda dengan nilai keseimbangannya, maka ada perbedaan antara sisi kanan dan sisi kiri persamaan (1) sebesar:

DE $=$ Employed ${ }_{\mathrm{t}}-\mathrm{a}_{0}+\mathrm{a}_{1}$ Dirivt

Persamaan ini disebut dengan kesalahan ketidakseimbangan atau disequilibrium error (Thomas, 1997: 383 seperti dikutip Insukindro, 1999). Selanjutnya dirumuskan fungsi biaya kuadrat periode tunggal yang dikembangkan oleh Domowitz dan Elbadawi (1987) seperti dikutip Insukindro (1999).

$$
\begin{aligned}
\mathrm{C}_{\mathrm{t}}= & \mathrm{b}_{1}\left[\text { Employed }_{\mathrm{t}}-\text { Employed }_{\mathrm{t}}\right]+ \\
& \mathrm{b}_{2}\left[\left(\text { Employed }_{\mathrm{t}} \text {-Employed }_{\mathrm{t}-1}\right)-\right. \\
& \left.\mathrm{f}_{\mathrm{t}}\left(\mathrm{Z}_{\mathrm{t}}-\mathrm{Z}_{\mathrm{t}-1}\right)\right]
\end{aligned}
$$

Employed adalah jumlah orang yang bekerja pada periode $t, Z_{t}$ adalah vektor variabel yang mempengaruhi jumlah orang yang bekerja dan dipengaruhi secara linear oleh angka investasi asing langsung (dirivt). $b_{1}$ dan $b_{2}$ adalah vector baris yang memmberi bobot masing-masing biaya, dan $\mathrm{f}_{t}$ adalah pembobot elemen $Z_{t}-Z_{t-1}$. Selanjutnya dilakukan minimisasi persamaan (3) terhadap Employed $_{t}$ dan substitusi $Z_{t}$ sebagai fungsi dari Dirvt $t_{t}$, maka menjadi persamaan:

Employed $_{\mathrm{t}}=\mathrm{g}_{0}+\mathrm{g}_{1}$ Dirivt $_{\mathrm{t}}+\mathrm{g}_{2}$ Dirivt $_{\mathrm{t}-1}+$
Keterangan:

$\mathrm{g}_{0}=\mathrm{a}_{0} \mathrm{~b}$

$\mathrm{g}_{1}=\mathrm{a}_{1} \mathrm{~b}+(1-b) \mathrm{f}_{1}$

$\mathrm{g}_{2}=-(1-b) f_{1}$

$\mathrm{g}_{3}=(1-b)$

$\mathrm{b}=\mathrm{b}_{1} /\left(\mathrm{b}_{1}+\mathrm{b}_{2}\right)$

Persamaan (4) adalah cerminan hubungan jangka pendek atau ketidakseimbangan. Hal ini beresiko ada variabel yang tidak stasioner, sehingga persamaan OLS menjadi tidak bermakna karena terjadi regresi lancung (lihat Gujarati, 2003). Untuk mengatasi masalah itu maka persamaan (4) perlu diparameterisasi ulang menjadi:

$\Delta$ Employed $_{\mathrm{t}}=\gamma_{0}+\gamma_{1} \Delta$ Dirvt $_{\mathrm{t}}+\gamma_{2}$ Dirivt $_{\mathrm{t}-1}+$

$$
\gamma_{2} \text { Ect }
$$

Keterangan:

Ect $=$ Dirvt $_{\mathrm{t}-1}-$ Employed $_{\mathrm{t}-1}$

Persamaan (5) berarti perubahan orang yang bekerja ( $\Delta$ Employed $_{\mathrm{t}}$ ) masa sekarang dipengaruhi oleh perubahan investasi asing langsung $\left(\Delta\right.$ Dirvt $\left._{t}\right)$ dan kesalahan ketidakseimbangan atau error correction term (ECT). Persamaan (5) ini yang digunakan dalam paper ini.

\section{HASIL PENELITIAN DAN PEMBAHASAN}

Sebelum melakukan analisis maka perlu dilakukan pengujian stasionaritas sebagai justifikasi penggunaan ECM. Artinya data jumlah orang yang bekerja dan nilai investasi langsung tidak stasioner sehingga perlu digunakan ECM. Pengujian stasionaritas dengan menggunakan Augmented Dickey 
Fuller test. Sebenarnya untuk model First Order ECM tidak perlu melakukan pengujian stasionaritas karena model ECM sendiri akan mengatasi masalah data yang tidak stasioner tadi. Namun demikian penulis perlu melakukan ini sebagai argumen penggunaan ECM. Tabel 4 menunjukkan hasil pengujian Augmented Dickey Fuller test untuk variabel employed.

Hasil pengujian menunjukkan nilai ADF lebih besar dibandingkan nilai kritis MacKinnon untuk nilai kritis 1 persen berarti variabel employed stasioner. Hasil uji ini nampak dalam Tabel 5.

Hasil pengujian menunjukkan nilai ADF untuk variabel investasi langsung lebih besar daripada nilai kritis yang berarti variabel ini juga stasioner.

Penggunaan regresi OLS sebenarnya cukup untuk menjelaskan hubungan antara jumlah orang yang bekerja dengan investasi asing langsung, namun demikian penggunaan ECM tetap lebih baik karena model ini memberikan penjelasan dalam jangka pendek maupun jangka panjang serta mengeliminasi pengaruh ketidakseimbangan, sesuatu yang nyata terjadi dalam perekonomian. Tabel 6 menunjukkan hasil pengujian ECM dengan program Eviews.

Selanjutnya untuk menguji apakah model ECM terkena masalah autokorelasi maka dilakukan pengujian dengan menggunakan Serial LM Test. Tabel 7 menunjukkan hasil pengujian LM test.

Hasil pengujian LM test menunjukkan ada masalah autokorelasi dari model ECM dalam paper ini. Hal ini menjelaskan mengapa nilai ECT tidak signifikan secara statistik. Untuk mengatasi hal ini maka model regresi di atas harus diperbaiki dengan menggunakan transfomasi data dengan nilai $\rho$ yang diperoleh dari nilai Durbin Watson. Rumus $\rho$ $=1-\mathrm{d} / 2$ (lihat Gujarati, 2003). Hasilnya adalah:

$$
\begin{aligned}
& \rho=1-0,964 / 2 \\
& \rho=0,518
\end{aligned}
$$

Data yang ada ditransformasi dengan nilai 0,518 sehingga untuk:

\begin{tabular}{|c|c|c|c|}
\hline ADF Test Statistic & -3.252890 & $\begin{array}{l}1 \% \text { Critical Value* } \\
5 \% \text { Critical Value } \\
10 \% \text { Critical Value }\end{array}$ & $\begin{array}{l}-3.8572 \\
-3.0400 \\
-2.6608\end{array}$ \\
\hline
\end{tabular}

Tabel 4. Hasil Pengujian ADF untuk Variabel Employed

* MacKinnon critical values for rejection of hypothesis of a unit root.

\begin{tabular}{|c|c|c|c|}
\hline ADF Test Statistic & -2.965332 & $\begin{array}{l}1 \% \text { Critical Value* }^{*} \\
5 \% \text { Critical Value } \\
10 \% \text { Critical Value }\end{array}$ & $\begin{array}{l}-3.8572 \\
-3.0400 \\
-2.6608\end{array}$ \\
\hline
\end{tabular}

Tabel 5. Hasil Pengujian ADF untuk Variabel Dirvt

*MacKinnon critical values for rejection of hypothesis of a unit root. 
employed $_{\mathrm{t}}^{*}=\left(\right.$ employed $_{\mathrm{t}}-0,518$ Employed $\left._{\mathrm{t}-1}\right)$ dan

Dirivt $_{t}=\left(\right.$ Dirivt $_{t}-0,518$ Dirivt $\left._{t-1}\right)$.
Adapun untuk data pertama maka transformasi yang dilakukan adalah Employed $_{t} \sqrt{ } 1$ $0,518^{2}$ dan Dirivt $\sqrt{ } 1-0,518^{2}$. Hasil analisis model yang telah ditransformasi adalah:

$\Delta \operatorname{TranEmploy}_{\mathrm{t}}=27490,8-0,547 \Delta$ Trandirvt $_{\mathrm{t}}-1,124$ Trandirivt $_{\mathrm{t}-1}+0,705$ Ect

$$
(3,137) \quad(-0,6511) \quad(-1,4366)
$$

\section{Tabel 6. Hasil Pengujian ECM}

Dependent Variable: DDIRIVT

Method: Least Squares

Date: 06/09/06 Time: 01:57

Sample(adjusted): 19842002

Included observations: 19 after adjusting endpoints

\begin{tabular}{lrlcc}
\hline \multicolumn{1}{c}{ Variable } & Coefficient & \multicolumn{1}{c}{ Std. Error } & t-Statistic & Prob. \\
\hline DEMPLYED & 3508.868 & 3418.924 & 1.026308 & 0.3210 \\
\multicolumn{1}{c}{ EMPLOYED(-1) } & -0.105285 & 0.231718 & -0.454365 & 0.6561 \\
$\quad$ ECT & -0.220992 & 0.164394 & -1.344281 & 0.1988 \\
\hline R-squared & -0.177874 & \multicolumn{1}{c}{0.156231} & -1.138528 & 0.2728 \\
Adjusted R-squared & 0.130175 & Mean dependent var & -133.8421 \\
S.E. of regression & -0.043790 & S.D. dependent var & & 1553.131 \\
Sum squared resid & 1586.772 & Akaike info criterion & & 17.76146 \\
Log likelihood & 37767687 & Schwarz criterion & & 17.96028 \\
Durbin-Watson stat & -164.7338 & F-statistic & & 0.748284 \\
& 0.964843 & Prob(F-statistic) & & 0.540069 \\
\hline
\end{tabular}

\section{Tabel 7. Hasil Pengujian LM test}

Breusch-Godfrey Serial Correlation LM Test:

\begin{tabular}{lrll}
\hline F-statistic & 6.761415 & Probability & 0.009707 \\
Obs*R-squared & 9.687268 & Probability & 0.007878 \\
\hline
\end{tabular}

Test Equation:

Dependent Variable: RESID

Method: Least Squares

Date: 06/09/06 Time: 02:00

\begin{tabular}{ccccc}
\hline Variable & Coefficient & Std. Error & t-Statistic & Prob. \\
\hline C & 708.8854 & 2578.675 & 0.274903 & 0.7877 \\
DEMPLOYED & -0.086922 & 0.184102 & -0.472141 & 0.6447 \\
EMPLOYED(-1) & -0.014386 & 0.293800 & -0.048964 & 0.9617 \\
ECT & -0.007194 & 0.293372 & -0.024522 & 0.9808 \\
RESID(-1) & 0.814643 & 0.264747 & 3.077061 & 0.0088 \\
RESID(-2) & -0.588596 & 0.437043 & -1.346769 & 0.2011 \\
\hline R-squared & 0.509856 & Mean dependent var & $-1.08 E-12$ \\
Adjusted R-squared & 0.321339 & S.D. dependent var & & 1448.518 \\
S.E. of regression & 1193.302 & Akaike info criterion & & 17.25892 \\
Sum squared resid & 18511597 & Schwarz criterion & & 17.55717 \\
\hline
\end{tabular}


Hasil analisis model ECM hasil transformasi ini valid karena berdasarkan t-statistik nilai ECT signifikan. Adapun variabel investasi asing langsung (FDI) ternyata tidak mempunyai pengaruh signifikan terhadap penambahan jumlah orang yang bekerja. Hal ini dapat diartikan peningkatan jumlah investasi asing langsung yang masuk ke Indonesia ternyata tidak mampu mengatasi masalah pengangguran. Hasil pengujian ini menunjukkan sesuatu yang tidak sesuai dengan kebijakan pemerintah untuk mengundang investor asing agar membuka pabrik di Indonesia, karena pembukaan pabrik baru itu ternyata tidak menyerap tenaga kerja. Hal ini berarti dalam setting Indonesia, hipotesis yang menyatakan ada pengaruh positif signifikan investasi langsung (FDI) terhadap peningkatan jumlah orang yang bekerja tidak didukung.

\section{Diskusi: Perlukah Kebijakan Industri?}

Inpres No 3/2006 yang dikeluarkan pemerintah bulan Maret lalu mengatur berbagai hal yang perlu dilakukan semua departemen untuk memperbaiki iklim investasi. Berdasarkan hasil empirik dari paper ini maka investasi asing yang masuk bisa jadi meningkatkan pertumbuhan ekonomi, namun tidak mengatasi masalah pengangguran, lalu apa yang salah?

Ada sesuatu yang tidak diperhatikan oleh pemerintah terkait dengan masalah investasi langsung. Pemerintah tidak memfokuskan arah investasi pada suatu industri tertentu. Mankiw (2003) dalam pembahasan tentang pertumbuhan ekonomi menegaskan perlunya adanya alokasi investasi ekonomi yang tepat. Analisis dengan Model Solow tentang pertumbuhan ekonomi menyatakan perlunya stimuli untuk mengarahkan investasi. Dalam bahasa yang mudah, maka kebijakan industri diperlukan untuk mengarahkan investasi yang berdampak besar bagi perekonomian suatu negara.

Amerika Serikat saat ini adalah negara yang percaya dengan mekanisme pasar sehingga mereka tidak melakukan kebijakan industri. Para ekonom AS inilah yang menjadi referensi ekonom Indonesia. Padahal jika kita menyadari, keberhasilan Korsel dan India dalam memperbaiki kinerja ekonomi adalah karena mereka melakukan kebijakan industri. Korea Selatan sejak kebangkitan ekonominya pada tahun 70-an mengarahkan industrinya pada sektor otomotif dan industri. Kebangkitan ekonomi India dari ejekan the Hindu's Economic Growth adalah karena orientasi industri yang diarahkan pada pengembangan teknologi informasi. Kelemahan utama, kebijakan industri adalah adanya campur tangan pemerintah yang terlalu banyak dalam perekonomian. Campur tangan pemerintah yang terlalu banyak ini jika tidak dikendalikan justru bisa mengakibatkan kegagalan pasar (market failure).

Klimenko (2004) mengemukakan dalam menerapkan kebijakan industri, pemerintah harus menentukan industri yang mempunyai keunggulan komparatif. Penilaian keunggulan komparatif ini dilakukan dengan melihat aspek-aspek analisis biaya, dampak jangka panjang dan teknologi. Terkait dengan kondisi di Indonesia, perbaikan iklim investasi dengan hasil tambahan investor yang masuk membangun pabrik baru, tidak cukup untuk mengatasi masalah pengangguran di Indonesia. Hal ini didukung oleh hasil empirik paper ini yang menyatakan tidak ada hubungan yang signifikan antara tambahan jumlah orang yang bekerja dengan tambahan FDI. Pemerintah harus mulai mengarahkan 
investasi langsung di Indonesia pada industriindustri yang mempunyai nilai strategis. Tingginya angka pengangguran terbuka di Indonesia seharusnya memberikan kesadaran pada pemerintah untuk mengarahkan investasi pada industri-industri padat karya. Hal ini bisa dilakukan dengan pemberian fasilitas dan kemudahan pada industri-industri tersebut.

\section{KESIMPULAN}

Penggunaan model ECM dari penelitian ini memberikan penjelasan bahwa jumlah orang yang bekerja tidak dipengaruhi oleh tambahan jumlah investasi asing yang masuk di Indonesia. Berdasarkan data dari Badan Pusat Statistik, investasi asing langsung yang masuk di Indonesia dalam kurun waktu tiga tahun terakhir hanya berada pada industri padat modal seperti industri farmasi dan otomotif (BPS, 2006).

Simpulan dalam paper ini memberikan kritik kepada pemerintah bahwa pemulihan iklim investasi yang bisa jadi berujung pada perbaikan realisasi investasi, tidak akan bisa menyelesaikan masalah tingginya angka pengangguran di Indonesia. Masalah pengangguran di Indonesia cenderung mengalami peningkatan dalam kurun waktu 5 tahun terakhir, padahal hampir semua indikator ekonomi makro mengalami perbaikan. Pemerintah perlu menganalisis lebih dalam tentang masalah pengangguran di Indonesia dengan melihat karakteristik dan kemungkinan solusinya.

Melihat contoh dari negara tetangga seperti Thailand, Korea Selatan dan India, pemerintah perlu mempertimbangkan penyusunan desain industrialisasi di Indonesia. Pemerintah perlu membuat cetak biru yang memberikan arah industri nasional. Dalam cetak biru itu perlu dianalisis industri-industri apa yang perlu diprioritaskan, apa keuntungan dan kerugian pengembangan industri tersebut, berapa biaya (ekonomi dan sosial) yang diperlukan dan yang paling penting apa dampaknya bagi perekonomian nasional secara keseluruhan termasuk apakah industri yang dikembangkan mampu mengatasi masalah pengangguran.

Paper ini mencoba menganalisis fenomena pengangguran terbuka di Indonesia yang semakin mengkhawatirkan. Pemerintah seharusnya menyadari perlu usaha yang lebih keras untuk mengatasi masalah pengangguran di negara ini.

\section{DAFTAR PUSTAKA}

Baier, Scott L dan Jeffrey $\mathrm{H}$ Bergstand (2001), the Growth of World Trade; Tariffs, Transport Costs, and Income Similarity, Journal of International Economics Vol 53 pp 1-27.

Byrne, David dan Eric Strobl (2004), Defining Unemployment in Developing Countries: Evidence from Trinidad and Tobago, Journal of Development Economics Vol 73 pp 465-476.

Demirbag, Mehmet dan Hafiz Mirza (2000), Factors Affecting International Joint Venture Success: an Empirical Analysis of Foreign-Local Partner Relationships and Performance in Joint Ventures in Turkey, International Business Review Vol 9, pp 1-35.

Dhanani, Shafiq, (2004), Unemployment and Underemployment in Indonesia, 19762000: Paradoxes and Issues, Research Paper, Geneva: International Labour Office. 
Greenaway, David, Wyn Morgan dan Peter Wright (2002), Trade Liberalization and Growth in Developing Countries, Journal of Development Economics Vol 67 pp 229-244.

Gujarati, Damodar (2003). Basic Econometrics, Boston: McGraw Hill International.

Insukindro (1991), Regresi Linear Lancung dalam Analisis Ekonomi: Suatu Tinjauan dengan Satu Studi Kasus di Indonesia, Jurnal Ekonomi dan Bisnis Indonesia, Vol 1 pp 88-23.

Insukindro (1999), Pemilihan Model Ekonomi Empirik dengan Pendekatan Koreksi Kesalahan, Jurnal Ekonomi dan Bisnis Indonesia (JEBI), Vol 14, No.1.

Kishi, Mashumi (2003), Foreign Direct Investment by Japanese Firms and Corporate Governance:in Relation of Monetary Policies of China, Korea and Japan, Journal of Asian Economics Vol 13, pp 731-748.

Kuncoro, Mudrajad (2000), Ekonomi Pembangunan; Teori, Masalah dan Kebijakan, Yogyakarta: UPP AMP YKPN.

BPS, (2006). Laporan Tahunan Badan Pusat Statistik, (Online) (http://www.bps.go. id, diakses 8 Agustus 2006)

Lipsey, Robert E dan Fredrik Sjoholm, (2004). Foreign Direct Investment,
Education and Wages in Indonesian Manufacturing, Journal of Development Economics Vol. 73.

Mankiw, Gregory N., (2003), Macroeconomics $5^{\text {th }}$ Edition, New York: Worth Publisher.

Ramstetter, Eric D., (2004) . Labor Productivity, Wages, Nationality, and Foreign Ownership Shares in Thai Manufacturing, 1996-2000, Journal of Asian Economics Vol 14 pp 861-884.

Roy, Sudipta Dutta (2004), Employment Dynamics in Indian industry: Adjustment Lags and the Impact of Job Security Regulations, Journal of Development Economics Vol 73 pp 233- 256.

Sanyal Rajib N dan Turgut Guvenli (2000), Relations between Multinational Firms and Host Government: the Experience of American-owned Firms in China, International Business Review Vol 9, pp 119-134.

UNCTAD (2004), Prospects for FDI flows, TNC Strategies and Promotion Policies: 2004-2007, Laporan Penelitian.

Zulkieflimansyah (2000), Orientasi Baru Industri Nasional dan Pentingnya Dukungan Kemampuan Teknologi dalam Usahawan, 25 (8) 